\title{
Associations between lexicon and grammar at the end of the second year in Finnish children
}

\section{Stolt, Suvi}

2009

Stolt , S , Haataja , L , Lapinleimu , H \& Lehtonen , L 2009 , ' Associations between lexicon and grammar at the end of the second year in Finnish children ', Journal of Child Language , vol. 36 , no. 4 , pp. 779-806 . https://doi.org/10.1017/S0305000908009161

http://hdl.handle.net/10138/309066

https://doi.org/10.1017/S0305000908009161

publishedVersion

Downloaded from Helda, University of Helsinki institutional repository.

This is an electronic reprint of the original article.

This reprint may differ from the original in pagination and typographic detail.

Please cite the original version. 
7. Child Lang. 36 (2009), 779-806. (c) 2008 Cambridge University Press doi:I0.1017/So305000908009161 Printed in the United Kingdom

\title{
Associations between lexicon and grammar at the end of the second year in Finnish children*
}

\author{
SUVI STOLT \\ University of Helsinki and Turku University Central Hospital, Finland
LEENA HAATAJA, HELENA LAPINLEIMU
AND LIISA LEHTONEN \\ Turku University Central Hospital, Finland
}

(Received 2 I September 2007. Revised 3 I March 2008. First published online I 2 November 2008)

\section{ABSTRACT}

The emergence of grammar in relation to lexical growth was analyzed in a sample of Finnish children $(\mathrm{N}=\mathrm{I} 8 \mathrm{I})$ at 2 ; 0 . The Finnish version of the Communicative Development Inventory was used to gather information on both language domains. The onset of grammar occurred in close association with vocabulary growth. The acquisition of the nominal and verbal inflections of Finnish differed when analyzed in relation to the lexicon in which they are used: the strongest growth in the acquisition of case form types occurred when the nominal lexicon size was roughly between 50 and 250 words, whereas verb inflectional types were acquired actively from the beginning of the verb lexicon acquisition. The findings extend the previous findings of the close association between lexicon and grammar (e.g. Bates \& Goodman, I 999). The results suggest that different grammatical structures display different degrees and types of lexical dependency.

[*] This study was supported by grants from the Emil Aaltonen Foundation, the Friends of Paediatric Clinics in University Hospitals in Finland Fund, the Neonatal Research in Southwestern Finland Fund, The Finnish Cultural Foundation, Langnet, the Finnish postgraduate school in language studies, and by the Academy of Finland. We thank Petriina Munck for recruiting the sample of 146 children, and Riikka Korja, Annika Lind, Petriina Munck and Anu Uschakoff, psychologists, for assessing the cognitive skills of the children at 2 ; o. We thank Jaakko Matomäki for help in data analyses. We are grateful for all the families for participating in this study. This study is part of the PIPARI study. The PIPARI study group comprises Mikael Ekblad, Satu Ekblad, Eeva Ekholm, Leena Haataja, Pentti Kero, Jarkko Kirjavainen, Riikka Korja, Harry Kujari, Helena Lapinleimu, Liisa Lehtonen, Annika Lind, Hanna Manninen, Jaakko Matomäki, Jonna Maunu, Petriina Munck, Pekka Niemi, Pertti Palo, Riitta Parkkola, Anniina Peltola, Jorma Piha, Liisi Rautava, Päivi Rautava, Milla Reiman, Hellevi Rikalainen, Katriina Saarinen, Elina Savonlahti, Matti Sillanpää, Suvi Stolt, Päivi TuomikoskiKoiranen and Tuula Äärimaa. Address for correspondence: Suvi Stolt, University of Turku, Faculty of Social Sciences/Logopedics, Itäinen Pitkäkatu 3a, 200I4 Turku, Finland. Email: suvi.stolt@utu.fi 
Contrary to the views that considered lexical and grammatical knowledge to be qualitatively distinct there have recently been proposals integrating the two language domains. In the field of linguistic theory it has been proposed that there is no strict division between lexical and syntactic constructions (e.g. Goldberg, I 999). The empirical findings of child language acquisition have shown a strong overall association between lexical and grammatical acquisition at the end of the second year in children acquiring different languages (e.g. Bates, Dale \& Thal, I995; Caselli, Casadio \& Bates, I 999). However, there are only a few studies in which the associations between lexicon and grammar are analyzed further in detail (Marchman \& Bates, I994; Thordardottir, Weismer \& Evans, 2002). The present study focuses on the association between the lexicon and grammar in Finnish children in a detailed manner. Finnish is an agglutinative language with an extensive nominal and verbal inflectional system. Because of its intensive inflectional system, Finnish is a good candidate for further analyzing the associations between lexicon and grammar. One aim of the present study was to test whether different grammatical structures (i.e. the nominal and verbal inflectional systems of Finnish) display different degrees or types of lexical dependency (Bates \& Goodman, I 997: 524).

\section{Aspects of the growth of lexicon and grammar at the end of the second year}

By the end of the second year most children have acquired a foundation for their lexicon, although the variation is high (Fenson, Dale, Reznick, Bates, Thal \& Pethick, I994; Lyytinen, I999). The emergence of grammar is detected in different ways. One route is via the finding that children acquire those lexical items which carry a heavy grammatical load (i.e. closed-class words) only after the acquisition of nouns and predicates have clearly begun. Thus their emergence has been regarded as a sign of grammatical growth (Bates et al., I994). The other sign is the onset of multiword combinations. According to the findings of the normative study of the Communicative Development Inventory (CDI, Fenson et al., r994) in children acquiring English, 57\% of the parents reported their children combined words at $\mathrm{I} ; 6$, and nearly all parents reported their children had word combinations at 2; (Fenson et al., I 994; Bates et al., I 995). If morphology is considered, children start with single unmarked or morphologically very simple forms at the beginning of the second year (e.g. Bittner, Dressler \& Kilani-Schoch, 2003; Clark, 2003). One form is used for each word, and there is no system of grammatical morphology yet (Bittner et al., 2003; Clark, 2003; Peters, I995). These first rote-learned forms differ in different languages (Bittner et al., 2003: 21). For instance, for verbs, the infinitive or the third person singular (S) present form, either inflected with a person marker (e.g. Dutch, German) or with the stem vowel (e.g. 780 
Lithuanian) or totally uninflected form (e.g. Turkish), are used (Bittner et al., 2003). In Finnish these first, early basic forms are for nominal words (i.e. nouns, adjectives, pronouns and numerals), the unmarked nominative (e.g. kukka 'flower') and partitive singular (e.g. vettä 'water'), and for verbs ${ }_{3} \mathrm{~S}$ present (e.g. nukkuu 'sleeps') and ${ }_{2} \mathrm{~S}$ imperative form (e.g. anna 'give!'; Laalo, 2002, 2003; Toivainen, I980). When the active growth of morphology begins at the end of the second year, there is an increase in inflectional types within a relatively short period. Children also start to extend the use of those inflectional types they have already used (Bittner et al., 2003: 23). Slightly later in their morphological development, the use of over-regularization errors can be detected in children's language (Marchman \& Bates, I 994; Clark, 2003). The emergence of these errors has been interpreted as a sign of productivity meaning that children are not only using rote-learned forms, but are also processing the rules behind the morphology (Marchman \& Bates, I 994; Marcus, I 996).

\section{Dual mechanism view versus single mechanism view}

A primary question in the discussion of the association between lexicon and grammar is whether these language domains are developing separately with different onset times and developmental rates, or together, that is, the onset of grammar is related to lexical size (Thordardottir et al., 2002). According to the dual mechanism view, the specific grammatical rule-based mechanism, independent of the lexicon, mediates the use and acquisition of inflectional morphology (Marcus, r 996; Pinker, r991). According to the single mechanism view, lexical items are stored, regularities between them detected and then organization takes place. The growth of morphology is associated with lexicon growth (Bates \& Goodman, I997; Marchman, Plunkett \& Goodman, I997; Thordardottir et al., 2002; Dionne, Dale, Boivin \& Plomin, 2003). In particular the finding that there is non-linear growth of grammatical measures in relation to lexicon growth has been considered evidence of a single mechanism view. (The non-linear interpretation comes from little or no effect of lexicon size on the growth of grammar in relation to small lexicons, but visible acceleration in the growth of grammar in association with large lexicons. The grammatical measures involved include syntactic complexity and verb inflectional morphologysee Bates \& Goodman, I 997, I 999; Caselli et al., I 999; Marchman \& Bates, I 994; Thordardottir et al., 2002). This finding has been interpreted to mean that children need to acquire the 'critical mass' of lexical items first before the emergence of grammar can be detected (Bates \& Goodman, I997; Marchman \& Bates, I 994; Thordardottir et al., 2002). The non-linearity in the grammatical acquisition in relation to lexicon growth has recently been questioned, however. Based on the reanalysis of the norming sample of the 
CDI data, Dixon \& Marchman (2007) suggested that children aged between I ; 4 and 2;6 developed lexicon and grammar synchronously, not in the non-linear manner.

The first empirical finding of the strong link between lexicon and grammar in children acquiring English was that the lexicon size at $\mathbf{I} ; 8$ was the strong predictor of grammatical growth (mean length of utterance analysed from spontaneous speech; MLU, $r=0.83$ ) at 2; . It was also a better predictor of this growth than the MLU value at I;8 (Bates, Bretherton \& Snyder, I988). Since then many empirical findings of the strong overall association between lexicon and grammar have been reported in English children (Anisfeld, Rosenberg, Hoberman \& Gasparini, I998; Bates et al., I988; Bates et al., I995; Bates \& Goodman, I997, I999; Dionne et al., 2003), and in children acquiring a language other than English as their first language (Italian: Caselli et al., ı999; Hebrew: Maital, Dromi, Sagi \& Bornstein, 2000; Icelandic: Thordardottir et al., 2002; German: Szagun, Steinbrink, Franik \& Stumper, 2006). In Finnish children, the associations between lexicon and grammar have not been analyzed in detail before. However, Lyytinen \& Lyytinen (2004) have presented high-correlation coefficient values between lexical and grammatical measures in Finnish children at 2;0. Though Lyytinen \& Lyytinen (2004) do not present a detailed analysis of the association between lexicon and grammar or discuss it in detail, the values do suggest a similar strong association in Finnish children between these language domains as reported in other languages.

Different proposals have been suggested to explain this reported strong link between lexicon and grammar. One is perceptual bootstrapping (Bates \& Goodman, I999). The small grammatical items, function words and bound morphemes, are short and unstressed in adult speech, and therefore hard to perceive. The acquisition of these items occurs after a number of content words (i.e. nouns, verbs) have been acquired. Thus, the content words provide a top-down structure which can be used in the perception and acquisition of the closed-class words and inflectional suffixes. Logical bootstrapping (Bates \& Goodman, I999) offers an explanation for a phenomenon detected in vocabulary acquisition: children first acquire names, then predicate terms and small grammatical items (i.e. a shift from reference to predication and to grammar; Bates et al., 1994). According to this view children cannot acquire relational terms before they have acquired enough words for the things to which predicate words relate. Bates \& Goodman (I999) propose that this logical bootstrapping could at least partially explain the close dependence of grammatical growth on lexical growth. Children may also use the conceptual information of the different types of words (i.e. nouns refer to peoples, things and places) to infer how words are used (i.e. as a noun or verb). This phenomenon, called semantic bootstrapping (Clark, 2003), offers a way for a child to get hold of word 
classes and of how different types of words are used in grammatical structures. The views presented explain the association between lexicon and grammar from the perspective of vocabulary growth. However, it has also been shown that children use syntactic information (i.e. sentence-level semantics, morphological cues, word order, prosody) to interpret the meaning of a new word. This capacity was first termed syntactic bootstrapping by Gleitman ( I990; see also Bates \& Goodman, I999; Clark, 2003). The use of syntactic information to interpret the meaning of a new word may at least partially explain the close dependency between lexicon and grammar at the end of the second year (Bates \& Goodman, I999). Thus, although different views have been offered, it is unclear what strategies children use when acquiring their lexical and grammatical knowledge. It is also possible that different strategies are in use at the same time. Dionne et al. (2003) studied lexical and grammatical development in over 2,500 pairs of twins and provided evidence that both semantic and syntactic bootstrapping were in use as children acquired their linguistic knowledge between ages 2; 0 and 3; o. Further, Moyle, Weismer, Evans \& Lindstrom (2007) studied longitudinal relationships between lexical and grammatical development in typical and late-talking children. They also found evidence for bidirectional bootstrapping between ages 2 ; 0 and $3 ; 6$. Late-talking children used more lexical bootstrapping and less syntactic bootstrapping, however, when compared to typically developing children.

Only a few studies have analyzed the associations between lexicon and grammar in detail. Since it is known that different grammatical structures emerge at different points of development, it is possible, as suggested by Bates \& Goodman (I997: 524), that individual grammatical forms display different degrees, or different types, of lexical dependence. It may also be that different structures need a critical number of lexical items within a specific class to emerge (Bates \& Goodman, I 997: 524). Marchman \& Bates (I994) analyzed the association between the past tense verb inflection and lexicon size in English children, and reported that the number of verbs learned resulted in qualitative growth in verb morphology. Thordardottir et al. (2002) analyzed the associations between lexicon size, the emergence of verb inflectional morphology and sentence complexity in Icelandic and English children at 2; 0 , and detected a non-linear relationship between lexicon size and the emergence of verb inflection and growth of sentence complexity in both groups. However, Icelandic children required a larger critical mass (i.e. lexical items learned) than English children before the grammatical regularity was found. Thordardottir et al. (2002) interpreted this as being related to the more complex inflectional system of Icelandic compared to English.

The present paper explores and describes the associations between lexicon and grammar in detail in Finnish children. Because there are two 
extensive inflectional systems in Finnish (see the short description of Finnish morphology below and in the Appendix), we thought this would provide an interesting source to study the possible associations between a specific inflectional system and a corresponding lexicon. The aim was to study whether these inflectional systems are acquired in close association with the lexicon in which they are used, which would support the single mechanism view, or if not, it would support the dual mechanism view. It was also asked whether it could be possible to detect different onsets and/or developmental trajectories between the nominal and verbal inflectional systems when analyzed in relation to the corresponding lexicon. If so, this would support the hypothesis set by Bates \& Goodman (1997: 524), that different structures display different degrees or types of lexical dependency.

\section{Relevant aspects of the target language}

Finnish is an agglutinative Finno-Ugric language in which grammatical and case relationships are expressed primarily using suffixes (Dasinger, I997; Toivainen, I997). The morphology is very rich, including extensive nominal and verbal inflectional and derivational systems. The fifteen case forms used for inflecting nominal words can be divided into three groups (grammatical, local and other cases; Dasinger, I997; Appendix). There is a fixed order of nominal suffixes (STEM + NUMBER + CASE + POSSESSIVE) and no grammatical gender marking in Finnish. In verbal inflections, there is a system of subject-verb agreement. In addition, the morphology for finite verbs can express voice (active, passive), mood (indicative, imperative, conditional, potential) and tense (past, non-past). The suffixes are added to the stem in the following order: STEM + TENSE/ MOOD + PERSON/NUMBER (Dasinger, I 997; Appendix).

\section{METHOdS}

\section{Participants}

The associations between lexicon and grammar were studied in a sample of I 8 I children. The children were participants in two separate studies. One sample consisted of I 46 children born at Turku University Hospital between November 200I and March 2004. The first healthy (i.e. normal birth weight, no admissions in the neonatal intensive care unit, born at 37 gestational weeks or later) boy and girl of the week were invited to the study in the maternity ward. A sample of 200 children was collected. The psychologist met I93 (98\%) of the children when they were 2 ; 0 , and the Finnish version of the Communicative Development Inventory (CDI, Fenson et al., I 994; FinCDI, Lyytinen, I999) was given to the families to be completed and returned by post within two weeks. The inventories of 
I64 $(85 \%)$ children were returned. Of those i 6 were excluded because a language or languages other than Finnish was used in the family and two because they were incompletely filled in. The final sample consisted of I 46 inventories of children growing up in monolingual Finnish-speaking families. The analysis of the composition of the lexicon at 2; o of some of these children $(\mathrm{N}=87)$ has been reported elsewhere (Stolt et al., 2007). The other sample consisted of 35 children. Children who were singletons, their mother's firstborns, and children of monolingual Finnish-speaking families were invited to the study in the maternity ward in Turku University Hospital. These children were born between November 200 I and April 2002. The language development of this group was followed from birth to 2 ; 0 years. In the present study the data gathered at 2;0 is presented. The detailed description of the lexical development of these 35 children between ages $0 ; 9$ and 2;0 is reported elsewhere (Stolt, Haataja, Lapinleimu \& Lehtonen, 2008). The children in these two groups formed two control groups in a multidisciplinary follow-up study (the PIPARI study; Lehtonen, Haataja, Lapinleimu and the study group) of the very-low-birthweight children approved by the Ethical Committee of the Hospital District of Southwest Finland in September 200I and in November $200 \mathrm{I}$ respectively.

From the sample of I 8 I children $92(5$ I $\%)$ were girls and $89(49 \%)$ boys. All the children were developing normally cognitively: the mental developmental index (MDI) of the group measured by a psychologist using the Bayley Scales of Infant Development (BSID II; Bayley, I993) at 2; о was i I ( $S D$ Iо, min. 84, max. I 28). Children grew up in middle- or upper-middle-class families: the length of the mothers' basic education was between nine and twelve years in $62(36 \%)$, and over twelve years in I 2 $(64 \%)$ mothers. The length of the father's basic education was under nine years in $7(4 \%)$, between nine and twelve years in $8 \mathrm{I}(49 \%)$ and over twelve years in $76(46 \%)$ fathers. The information on the basic education of seven mothers and seventeen fathers was missing. None of the subjects used a hearing aid or had a diagnosed hearing impairment at the 2;0 appointment.

\section{Data collection}

The standardized Finnish version of the CDI (FinCDI; Fenson et al., I 994; Lyytinen, I 999) was used to collect the data of lexicon and grammar. As explained above, to collect the data of the children in the larger sample $(n=\mathrm{I} 46)$, the FinCDI was given to the families by a psychologist when the children were 2 ; o. The families were asked to fill in the inventory and send it back by post within two weeks. The mean age of the children was $2 ; 0 \cdot 12$ ( $S D$ i I days) at the time the FinCDI form was completed. The children in the longitudinal cohort were met with their mother when they were 2;0 
(+2 weeks). The parents were asked to bring a completed FinCDI form to the appointment and the FinCDI was reviewed together with the mother. The criteria for a word ( 1 : spontaneous, not only imitated, use of the word; 2: connects the word repeatedly to the same referent) used in the present study are specified in the FinCDI form. These criteria were available to the parents of both samples.

There are 595 items presented in twenty semantic categories in the vocabulary checklist of the FinCDI. There are three sections measuring grammatical complexity in the grammar part. The first section in the grammar part measuring nominal inflections 'The plural ending and case forms' has nine subsections each reflecting a single, most typical morphological ending of nominals in Finnish (plural ending, genitive, partitive, inessive, elative, illative, adessive, ablative and allative). The second part 'Verb inflections' has seven subsections each asking about the use of a single verbal inflection (the ${ }_{2} \mathrm{~S}$ imperative, ${ }_{3} \mathrm{~S}$ negative present tense, ${ }_{3} \mathrm{~S}$ indicative present tense, $\mathrm{I} S$ indicative present tense, ${ }_{3} \mathrm{~S}$ indicative preterite, passive, and ${ }_{3} \mathrm{~S}$ indicative perfect). Each subsection presents one suffix, gives examples of its use and asks parents to indicate whether their child uses the suffix 'never', 'sometimes' or 'often'. The third part evaluates whether the child combines words (yes or no). The parents are also asked to write out the three longest utterances they have heard their child say recently.

\section{Data coding}

The following measures were used for the classification of the lexical data: ( I) lexicon size (i.e. all the words marked in CDI); (2) noun lexicon (words marked in the 'peoples' or 'places to go' categories were excluded; Bates et al., I 994); (3) verb lexicon (i.e. action words); and (4) closed-class words (i.e. pronouns, question words, prepositions, quantifiers and connecting words). In addition, a fifth measure was created for the purposes of the present study: (5) nominal lexicon (i.e. common nouns, adjectives and pronouns; there are no numeral words in the FinCDI). This was done to analyze the growth of the nominal inflectional types in relation to the lexicon in which these inflections are mainly used. The predicate category (verbs and adjectives; Bates et al., i 994) was not used, because the aim was to concentrate on the possible association between verbs and verbal inflectional types. The category of social terms (Caselli et al., I 999) was not used, because it includes words typical of very early lexical acquisition which children use in varying ways. This category was considered unsuitable for the aims of the present study (i.e. association between lexicon and grammar). Neither was the category of words about time included in the analysis as has been done in earlier studies (e.g. Bates et al., I994). 
TABLE I. Lexicon, nominal lexicon and verb lexicon size subgroups and the number of children in each subgroup

\begin{tabular}{|c|c|c|c|c|c|}
\hline $\begin{array}{l}\text { Lexicon size } \\
<5 \mathrm{I}: n=2 \mathrm{I}\end{array}$ & $5 \mathrm{I}-\mathrm{I} 00: n=\mathrm{I} 3$ & $\mathrm{IOI}-200: n=22$ & $20 \mathrm{I}-300: n=29$ & $30 \mathrm{I}-400: n=45$ & $>400: n=5$ \\
\hline $\begin{array}{l}\text { Nominal lexic } \\
\mathrm{I}-25: n=\mathrm{I} 7\end{array}$ & $\begin{array}{l}\text { n size } \\
\qquad 26-50: n=\mathrm{I} 2\end{array}$ & $5 \mathrm{I}-\mathrm{I} 00: n=\mathrm{I} 9$ & IOI $-200: n=53$ & $>200: n=78$ & \\
\hline \multicolumn{6}{|c|}{ Verb lexicon size } \\
\hline $\mathrm{I}-9: n=29$ & I0 $-24: n=\mathrm{I} 9$ & $26-50: n=29$ & $5^{\mathrm{I}-75: n=43}$ & $>75: n=53$ & \\
\hline
\end{tabular}

Adjectives, social terms and words about time were, however, included in the lexicon size. There is no category of helping verbs in the FinCDI.

The grammatical data was coded as follows. In the first two parts of the grammar section of FinCDI, the answers were coded as 'no' (= not yet) and 'yes' (= sometimes, often). The number of yes-answers was counted. Each child got a number of case form types (plural form included) which could vary between $\circ$ and 9 , and a number of verb inflectional types which could vary between $\circ$ and 7 in individual children. The mean number of the morphemes $\left(\mathrm{M}_{3} \mathrm{~L}\right)$ was counted for each child from the three longest sentences reported by the parents. Frozen phrases (songs, counting, etc.) were excluded. Whether the child combines words (yes/no) was coded.

\section{Analysis}

To describe the overall associations between lexicon and grammar, all lexicons were divided into subgroups according to lexicon size in the FinCDI (Bates et al., I 994, Bates \& Goodman, I997; see Table I), and the emergence of grammar (growth of morphological inflectional types and $\mathrm{M}_{3} \mathrm{~L}$, emergence of word combinations) was described in relation to vocabulary growth. The lexicon size subgroups were used also to analyze the quantitative and qualitative growth of the increase of the case form and verb inflectional types: the growth of case form types was analyzed in relation to the growth of nominal lexicon size, and the growth of the verb inflectional types in relation to the growth of the verb lexicon (Table I). Two children had no nominal words in their lexicon and eight children had no verbs, and the data of these children were excluded from this part of the analysis.

The analysis of the qualitative growth of the case form and verb inflectional types was based on the analysis of the first inflectional types used by Finnish children (i.e. basic forms: nominative and partitive in nominal inflectional types, ${ }_{3} \mathrm{~S}$ indicative present, ${ }_{2} \mathrm{~S}$ imperative in verb inflectional types; Laalo, 2002, 2003; Toivainen, I980). Using the analysis of the basic forms we aimed to identify roughly the point at which, in relation to the size of the corresponding lexicon, children start to produce inflectional 
types other than just those few, early lightly marked ones. Further, in Finnish verbs are not categorized into regular and irregular ones (Häkkinen, 200I), and such verb use is not mapped out in the FinCDI. Thus, the parallel procedure followed in earlier studies (Marchman \& Bates, I994; Thordardottir et al., 2002) was unsuitable for the present context.

\section{Reliability and validity}

The English version of the CDI has proved reliable and valid (Fenson et al., I994), as has the FinCDI. In the normative study of the FinCDI, the correlation between lexicon size in FinCDI and the result of the expressive scale in the Reynell Developmental Language Scale (RDLS) was strong $(r=0.85, p \leqslant 0.00 \mathrm{I})$, as was the correlation between the number of morphological inflectional types in FinCDI and the result of expressive scale in the RDLS $(r=0.74, p \leqslant 0.00 \mathrm{I})$ at $\mathrm{I} ; 6$ (Lyytinen, I 999). Further, to validate the parental report data, Lyytinen \& Lyytinen (2004) analyzed the maximum sentence length and the same inflectional types measured in FinCDI from an 8-minute sample of videotaped free-play sessions, and compared these values to those reported by the parents of the same children (children with familial risk for dyslexia, $n=107$; children with no risk for dyslexia, $n=93$ ). The correlations between the FinCDI scores and those derived from spontaneous speech varied between 0.73 and 0.85 , being highly significant $(p<0.00 \mathrm{I})$ for both groups.

To verify the information gathered using the FinCDI in the present study, the lexical and morphological information was analyzed from spontaneous speech when children were 2 ; o. This data was available for 35 children only. The ro-minute sample of children's speech was analyzed from the videotaped mother-child interaction by a two-member team (one a professional in the Finnish language, the other a professional in child language), both native speakers of Finnish. Only clear cases were analyzed. The total number of all word types, nominal word types (i.e. nouns, adjectives, pronouns and numerals), verb types, and inflectional types used (case forms and verb inflectional types separately), were calculated. For the lexical data, the pronoun and demonstrative pro-adverb types were counted according to their position in a sentence: different pronoun forms (tähän kirjaan 'into this book', tässä kirjassa 'in this book') were considered different inflected forms of the same word type; the demonstrative pro-adverbs were counted as different word types (tähän minä sen laitoin 'I put it in here', tässä se on 'here it is'). Combined verb forms were counted as one verb type (e.g. on $\overline{m e n n y t}$ ' has gone'). For the morphological data, the use of case endings in demonstrative pro-adverbs was analyzed as case forms (e.g. ABLATIVE: tuolta 'from there'; ADESSIVE: täällä 'here'; see Appendix) as has been done in earlier studies (Laalo, 2002; 
Toivainen, I997). The only exception was the demonstrative adverb not having the inflectional suffix of modern Finnish (i.e. the -nne-forms, e.g. tonne 'there', tänne 'here'), which were excluded from the analysis of the case forms (compare Laalo, 2002; Toivainen, I 997). If the plural form was used, it was included in the total number of case form types. The accusative (nominative- or genitive-accusative) was analyzed as one form. Spearman's correlational coefficients between the lexical and morphological values derived from data gathered using the FinCDI and analyzed from spontaneous speech were calculated. In addition, for the total sample of 18 I children, the Pearson's correlation coefficient values for the MDI value in BSID II and the total number of words in the lexicon in FinCDI, and for the MDI value and the total number of inflectional types in FinCDI were calculated.

\section{Statistics}

Associations between continuous variables were studied using the correlation coefficients. The Pearson's and Spearman's correlations were highly parallel for the large sample $(N=\mathrm{I} 8 \mathrm{I})$, and only the Pearson's correlations are reported. For the correlations giving information on the association between lexicon and grammar (lexicon size and the total number of morphological inflectional types, lexicon size and $\mathrm{M}_{3} \mathrm{~L}$, nominal and verbal lexicon sizes and nominal and verbal inflectional types) the coefficients of determination $\left(r^{2}\right)$, which are measures of the proportion of variance shared by the two variables, are also presented to describe the effect sizes. The Wilcoxon two-sample test was used to analyze the difference in the lexicon size between those children combining words and those who did not. A logistic regression analysis was used to study the effect of the growth of nominal and verb lexicon size on the emergence of other than basic inflectional types in morphology. To analyze the associations between the values derived from FinCDI and analyzed from spontaneous speech (lexical values vs. lexical values, grammatical values vs. grammatical values) for the sample of 35 children, the Spearman's correlation coefficient values were used. The results were considered significant if the $p$-value was $<0.05$. All the significance tests were 2-tailed. All the statistical analyses were performed with SPSS for Windows (1 2.0, SPSS Inc.) or SAS for Windows (9. I, SAS Institute inc.).

\section{RESULTS}

\section{Data description}

Mean and standard deviations for the lexical and grammatical measures, and the percentages of nouns, verbs, grammatical function and nominal words calculated from the total number of words in the lexicon are 
TABLE 2. Means, standard deviations $(S D)$, minimum-maximum values (Min.-Max.). The proportions of the nouns, verbs, closed-class and nominal words counted from the total number of words in the lexicon are presented on the right

\begin{tabular}{|c|c|c|c|}
\hline Measures & Mean $(S D)$ & Min.-Max. & $\%$ \\
\hline \multicolumn{4}{|l|}{ Lexicon } \\
\hline Total number of words & $285 \cdot 6\left(\right.$ I $\left._{5} 6 \cdot 8\right)$ & $5-58 \mathrm{I}$ & \\
\hline Nouns & I $39 \cdot 6(72 \cdot 6)$ & $0-254$ & 48 \\
\hline Verbs & $50 \cdot 2(34 \cdot 4)$ & $0-106$ & I 5 \\
\hline Closed-class words & $2 \mathrm{I} \cdot 9(\mathrm{I} 6 \cdot 3)$ & $0-7 \mathrm{I}$ & 7 \\
\hline Nominal words & I $62 \cdot 5(88 \cdot 4)$ & $0-325$ & 55 \\
\hline \multicolumn{4}{|l|}{ Morphology } \\
\hline Inflectional types/total & $10 \cdot 0(5 \cdot 0)$ & $0-16$ & \\
\hline Case form types & $5 \cdot 5(3 \cdot 1)$ & ০-9 & \\
\hline Verb inflectional types & $4 \cdot 5(2 \cdot 0)$ & $0-7$ & \\
\hline $\begin{array}{l}\text { Mean value of the longest utterances } \\
\text { Combines words } / \% \text { of the children }\end{array}$ & $\begin{array}{c}6 \cdot \mathrm{I}(3 \cdot 3) \\
\mathrm{I} 62(89 \cdot 5 \%)\end{array}$ & & \\
\hline
\end{tabular}

presented in Table 2 . There was a high variation in lexical and grammatical development between individual children at 2 ; 0 . The lexicon of these ${ }_{1} 8 \mathrm{I}$ Finnish children at 2 ; o consisted of $48 \%$ nouns, I $5 \%$ verbs and $7 \%$ grammatical function words. The mean value of the morphological inflectional types was ıо $(S D 5)$. The majority of the children $(90 \%)$ combined words.

\section{Overall associations between lexicon and grammar}

The correlation coefficient values between lexicon size and grammar were strong. The Pearson's correlation coefficient value for the lexicon size and the morphological inflectional types was $\left(r=0.88, p<0.000 \mathrm{I}\left(r^{2}=0.77\right)\right)$, and for the lexicon size and the $\mathrm{M}_{3} \mathrm{~L}\left(r=0.78, p<0.000 \mathrm{I} \quad\left(r^{2}=0.6 \mathrm{I}\right)\right)$. The emergence of the word combinations was associated with the lexicon size. The mean value of the lexicon size in children combining words $(n=\mathrm{I} 62)$ was $3 \mathrm{I} 3.67(S D \mathrm{I} 40.8 \mathrm{I}, \min .33, \max .58 \mathrm{I})$, and in those who did not $(n=\mathrm{I} 9) 46.37$ words $(S D 33.73$, min. 5, max. I 6$)$, $(\mathrm{W}=305$, $p<0.000 \mathrm{I})$.

When grammatical growth was considered in relation to lexicon size (Table 3), the trend was clear: children acquired grammar in accordance with vocabulary growth. The mean value of the morphological inflectional types was $\mathrm{I}_{9} 9\left(S D_{\mathrm{I}} \cdot 3\right)$ when the lexicon size was $<5 \mathrm{I}$ words. As lexicon size grew the number of morphological inflectional types increased. $\mathrm{M}_{3} \mathrm{~L}$ and the percentage of the children having word combinations grew in relation to vocabulary size. 
TABLE 3. The growth of the word classes and grammar in relation to the lexicon growth. Mean values and standard deviations are presented. The percentages counted from the total number of the words in the Finnish version of the Communicative Development Inventory (FinCDI) are presented for the lexical measures

\begin{tabular}{|c|c|c|c|c|c|c|c|c|c|}
\hline \multirow[b]{3}{*}{ Measures } & \multicolumn{9}{|c|}{ Lexicon size subgroups } \\
\hline & \multicolumn{3}{|c|}{$<5$ I $n=2$ I } & \multicolumn{3}{|c|}{$5 \mathrm{I}-\mathrm{I} O 0 \quad n=\mathrm{I} 3$} & \multicolumn{3}{|c|}{$10 \mathrm{I}-200 n=22$} \\
\hline & Mean $(S D)$ & $\%$ & Min.-max. & Mean $(S D)$ & $\%$ & Min.-max. & Mean $(S D)$ & $\%$ & Min.-max \\
\hline \multicolumn{10}{|l|}{ Lexicon } \\
\hline Nouns & I2 (8) & 33 & $0-28$ & 39 ( го) & 52 & $26-59$ & $83(23)$ & 54 & $50-123$ \\
\hline Verbs & I (I) & 5 & $0-4$ & $5(4)$ & 6 & $0-12$ & I7 ( IO) & II & $4-35$ \\
\hline Closed-class words & I (2) & 4 & o-8 & $5(2)$ & 6 & $2-8$ & $9(4)$ & 6 & $\mathrm{I}-\mathrm{I} 9$ \\
\hline Nominal words & I3 (9) & 37 & $0-30$ & 43 ( I I) & 57 & $27-6$ I & 9I (24) & 59 & $5^{6-1} 30$ \\
\hline \multicolumn{10}{|l|}{ Morphology } \\
\hline Inflectional types/Total & $\mathrm{I} \cdot 9(\mathrm{I} \cdot 3)$ & & $0-4$ & $3 \cdot 5(\mathrm{I} \cdot 4)$ & & $2-6$ & $7 \cdot 3(2 \cdot 6)$ & & $3^{-12}$ \\
\hline Case form types & $0.8(\mathrm{I} \cdot 0)$ & & $0-3$ & $\mathrm{I} \cdot 5(\mathrm{I} \cdot \mathrm{I})$ & & $0-4$ & $3 \cdot 6(\mathrm{I} \cdot 9)$ & & $\mathrm{I}-7$ \\
\hline Verb inflectional types & $\mathrm{I} \cdot \mathrm{I}(0 \cdot 7)$ & & $0-3$ & $\mathrm{I} \cdot 9(0 \cdot 6)$ & & $\mathrm{I}-3$ & $3 \cdot 7(\mathrm{I} \cdot \mathrm{I})$ & & $2-6$ \\
\hline$M_{3} L$ & I.9 $(0.9)$ & & $I \cdot 0-4 \cdot 7$ & $3 \cdot I(I \cdot 2)$ & & $I \cdot 3-5 \cdot 0$ & $4 \cdot I(I \cdot 7)$ & & $\mathrm{I} \cdot 3-7 \cdot 7$ \\
\hline \multirow[t]{3}{*}{ Combines words } & $8(38 \%)$ & & & $9(69 \%)$ & & & $20(9 \mathrm{I} \%)$ & & \\
\hline & \multicolumn{3}{|c|}{$201-300 n=29$} & \multicolumn{3}{|c|}{$30 \mathrm{I}-400 n=45$} & \multicolumn{3}{|c|}{$>400 n=5 \mathrm{I}$} \\
\hline & Mean $(S D)$ & $\%$ & & Mean $(S D)$ & $\%$ & & Mean $(S D)$ & $\%$ & \\
\hline \multicolumn{10}{|l|}{ Lexicon } \\
\hline Lexicon size & $24 \mathrm{I}(27)$ & & $203-283$ & $357(3 \mathrm{I})$ & & $303-400$ & $464(5 \circ)$ & & $402-58 \mathrm{I}$ \\
\hline Nouns & I 29 (I6) & 54 & $93^{-\mathrm{I}} 5^{8}$ & I 80 ( I 9) & $5 \mathrm{I}$ & I $26-2$ I I & 2 I $2(20)$ & 46 & I 7 I-254 \\
\hline Verbs & $37($ I I ) & I5 & I9-58 & 66 (го) & I 8 & $45-92$ & $90(9)$ & 20 & 68-1 о6 \\
\hline Closed-class words & I 5 (5) & 6 & $7-25$ & $25(7)$ & 7 & I $3-37$ & 4I（I2) & 9 & I 5-7 I \\
\hline Nominal words & I 45 ( I 7) & 60 & IO8-I 74 & $206(2 \mathrm{I})$ & 58 & I $54-238$ & $258(30)$ & 56 & 2 I $3-325$ \\
\hline \multicolumn{10}{|l|}{ Morphology } \\
\hline Inflectional types/Total & $9 \cdot I(3 \cdot I)$ & & $3^{-1} 5$ & I2.I $(2 \cdot 7)$ & & $5^{-16}$ & $14.7(2 \cdot 0)$ & & $8-\mathrm{r} 6$ \\
\hline Case form types & $4 \cdot 9(2 \cdot 0)$ & & $\mathrm{I}-9$ & $6 \cdot 8(2 \cdot 0)$ & & $2-9$ & $8 \cdot 4(I \cdot 3)$ & & $4-9$ \\
\hline Verb inflectional types & $4 \cdot 2(I \cdot 4)$ & & $\mathrm{I}-6$ & $5 \cdot 2(0.9)$ & & 3-7 & $6 \cdot 3(0 \cdot 8)$ & & $4-7$ \\
\hline$M_{3} L$ & $5 \cdot 5(\mathrm{I} \cdot 9)$ & & $2 \cdot 7-10 \cdot 0$ & $7 \cdot 1(2 \cdot 0)$ & & $3 \cdot 0-12 \cdot 0$ & $8 \cdot 9(3 \cdot I)$ & & $4 \cdot 0-21 \cdot 0$ \\
\hline Combines words & $29(100 \%)$ & & & $45(100 \%)$ & & & 5 I $(100 \%)$ & & \\
\hline
\end{tabular}

$\mathrm{M}_{3} \mathrm{~L}=$ Mean length of the three longest utterances reported in FinCDI counted in morphemes, $n=$ number. 


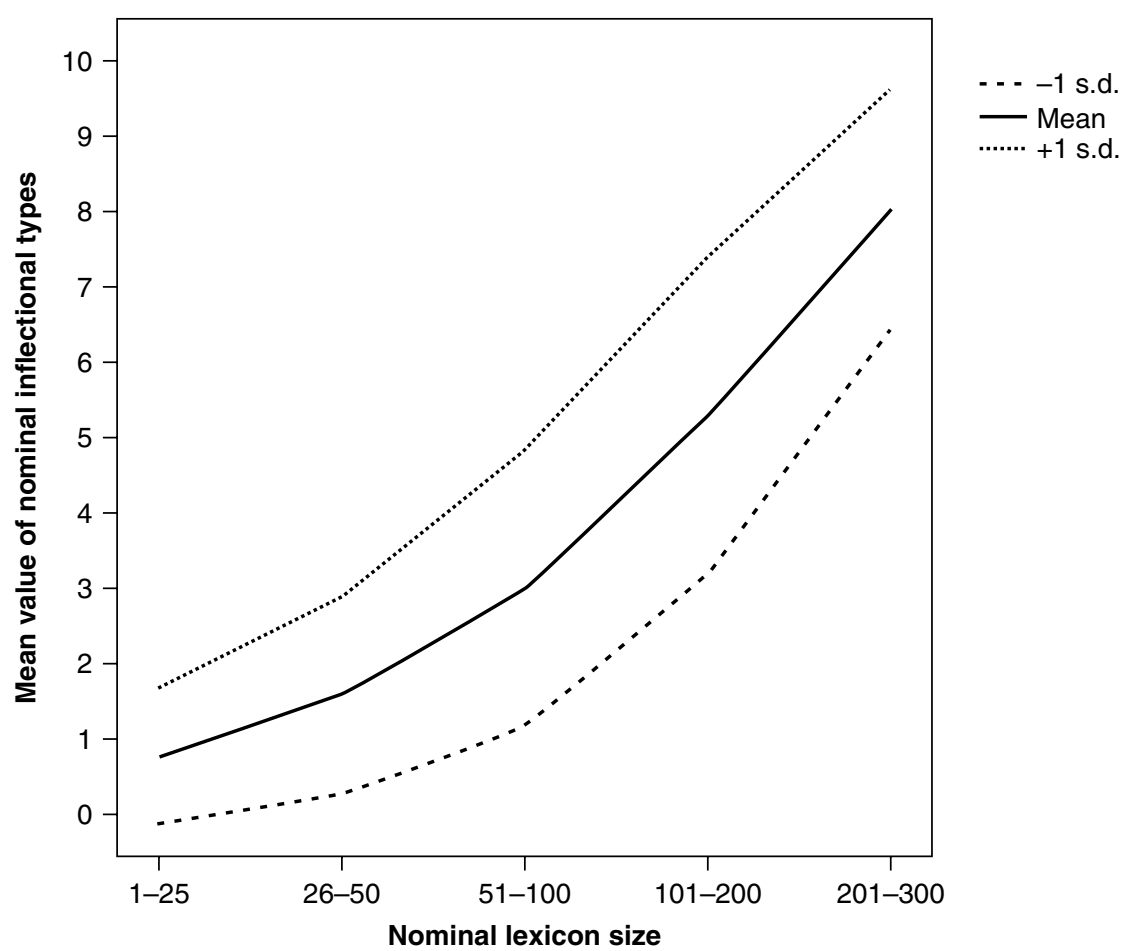

Fig. I. The growth of the case form types as a function of nominal lexicon size.

Associations between nominal and verb inflectional types and respective lexicon

Nominal lexicon and case form types. The most often used nominal inflectional types were partitive, illative and genitive (nominative is not mapped out in FinCDI). Elative and ablative were the local cases used the least. When the growth of the case form types was analyzed in relation to the growth of the nominal lexicon, children had only one case form type until the nominal lexicon had increased to $5 \mathrm{I}-\mathrm{I} 00$. After that the number of case form types began to increase (Figure I, Figure 2). The mean values and standard deviations for the case form types in the nominal lexicons of different sizes were: I-25 nominal words: 0.8 ( $S D$ 0.9); 26-50: I.6 ( $\left.S D_{\text {I }} \cdot 3\right)$; 5I-IOO: $3 \cdot 0(\mathrm{I} \cdot 9)$; IOI-200: $5 \cdot 3(2 \cdot \mathrm{I})$; > $200: 8 \cdot 0(\mathrm{I} \cdot 6)$.

The transition from the use of early basic forms to the emergence of other case form types in relation to the growth of the nominal lexicon size was analyzed by calculating the percentage of those children using other than just the partitive (singular) form in each nominal lexicon subgroup (the use of the unmarked nominative form is not asked in the FinCDI). The percentage of these children increased in relation to the nominal lexicon 


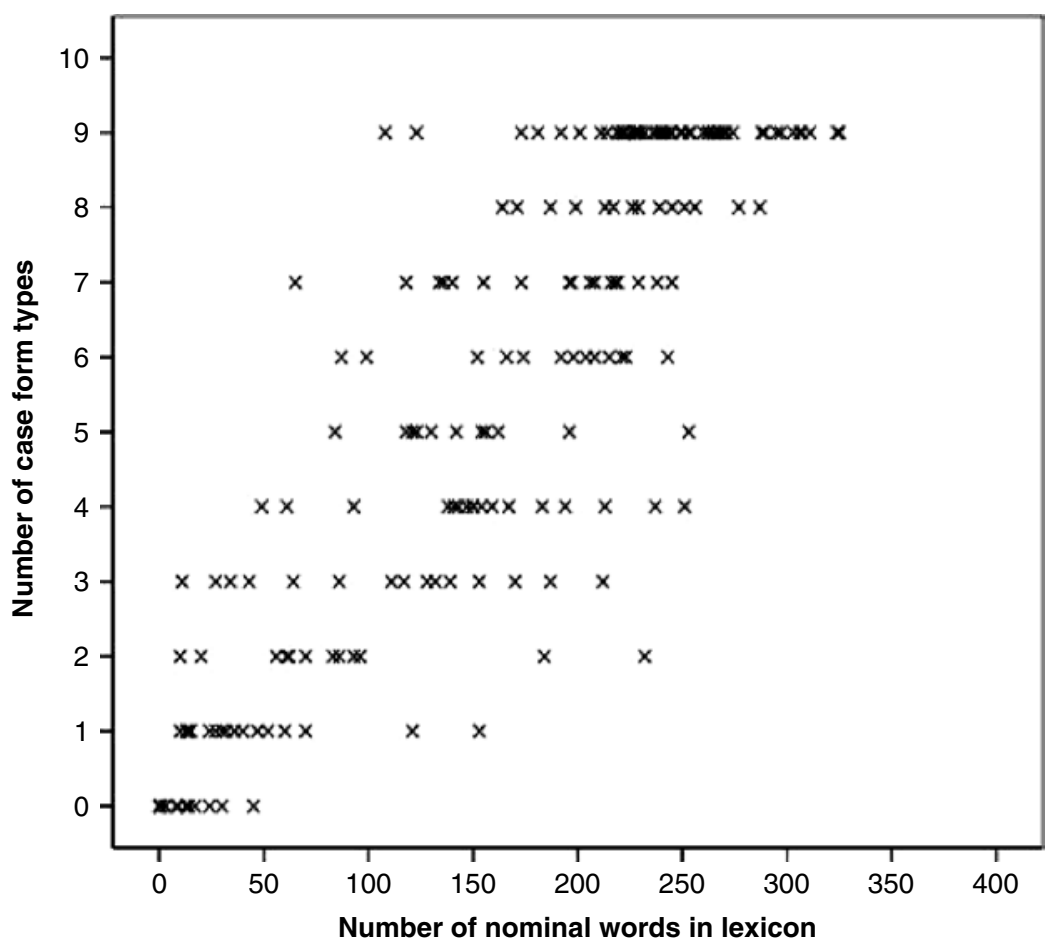

Fig. 2. The number of case form types in relation to the number of nominal words in the lexicon.

size ( $\mathrm{I}-25$ nominal words: $29.4 \%$ of the children used other than partitive form only; 26-50: 4I.7\%; 5I-100: 100\%; I0I-200: 100\%; >200: 100\%; see Figure 3). The nominal lexicon size predicted the use of other than just basic case form types: the odds ratio estimate $0.93, p<0.000 \mathrm{I},(95 \%$ confidence interval $0.89-0.96$ ). When the number of nominal words increased by one word, the odds that a child would have basic case form types only decreased by a factor of 0.93 .

Verb lexicon and verb inflectional types. The most used verb inflectional types were the $2 \mathrm{~S}$ imperative, ${ }_{3} \mathrm{~S}$ indicative present, ${ }_{3} \mathrm{~S}$ negative construction and ${ }_{3} \mathrm{~S}$ preterite form. Verb inflectional types were acquired in accordance with the growth of the verb lexicon size. The mean value of verb inflectional types in different verb lexicon size subgroups were: $\mathrm{I}-9$ verbs: mean 2.0 ( $S D$ I.I $)$; IO-25:3.2 (I·2); 26-50:4.4 (I·3); 5I-75:5.2 (I·O); $>75: 6 \cdot 2(0 \cdot 9$; see Figure 4, Figure 5).

The transition from the use of basic inflectional types to the use of other inflectional types was analyzed by counting the percentage of those children 


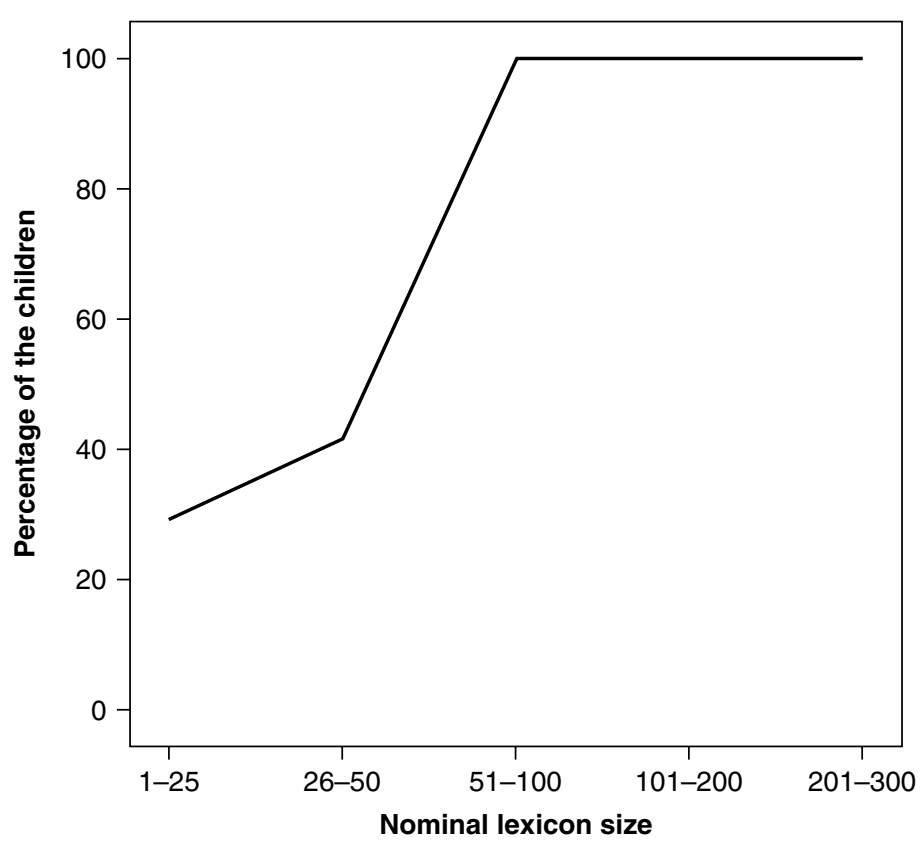

Fig. 3. The percentage of the children reported to have other case form types than basic forms only (nominative and partitive singular forms) in relation to the growth of the nominal lexicon size.

having verb inflectional types other than just the two basic ones in each verb lexicon subgroup. The percentage of these children increased in relation to the growth of the verb lexicon size: $\mathrm{I}-9$ verbs: $48 \cdot 3 \%$ of the children also used other than just basic verb inflectional types; Io-25:68.4\%; 26-50: $95.6 \% ; 5 \mathrm{I}-75:$ 100\%; $>75:$ 1 $00 \%$ (see Figure 6 ). The verb lexicon size predicted the use of other than just the basic forms: the odds ratio estimate $0.88, p<0.00$ I $(95 \%$ confidence interval $0.82-0.94)$. When the number of verbs increased by one word, the odds that a child would have only basic verb inflections decreased by a factor of 0.89 .

To get even more information about the possible associations between lexicon and grammar in Finnish children at 2; o, the correlation coefficient values between nominal lexicon and verb inflectional types, and verb lexicon and nominal inflectional types, were calculated. The results suggested strong overall associations between lexicon and grammar (nominal lexicon size vs. case forms types $(r=0.84)$, nominal lexicon size vs. verb inflectional types $(r=0 \cdot 86)$, verb lexicon vs. verb inflectional types $(r=0 \cdot 84)$, verb lexicon size vs. nominal inflectional types $(r=0 \cdot 83))$. All 


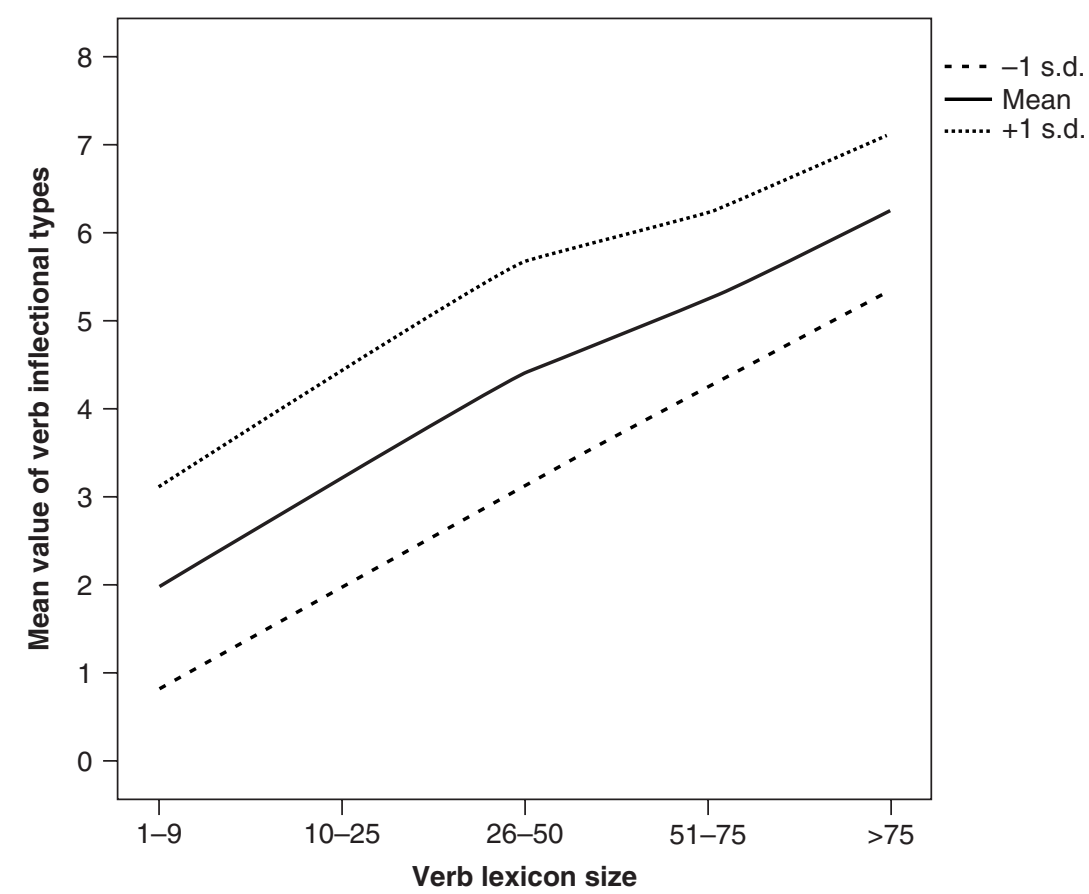

Fig. 4. The growth of the verb inflectional types as a function of the verb lexicon size.

correlation coefficient values were significant in the level $p<0.000 \mathrm{I}$. The $r^{2}$-values of these correlation coefficients varied between 0.69 and 0.74 .

\section{Correlations between the values derived from different measures}

The Spearman's correlation coefficient values between the lexical and morphological measures derived from the FinCDI and spontaneous speech for the sample of 35 children are presented in Table 4. All other values, except the one between the nominal lexicon size measured using the FinCDI and the number of nominal words used during the ro-minute videotaped interaction, were significant. The order of appearance of the same inflectional types measured in FinCDI, in the spontaneous speech in the sample of 35 children is presented in Table 5 .

The Pearson's correlation coefficients between the values derived from FinCDI and the MDI value for the total sample of i $8 \mathrm{I}$ children were: lexicon size: $r=0.76$; inflectional types: $r=0.78 ; \mathrm{M}_{3} \mathrm{~L}: r=0.70$. All values are significant in the level $p<0.000 \mathrm{I}$. 


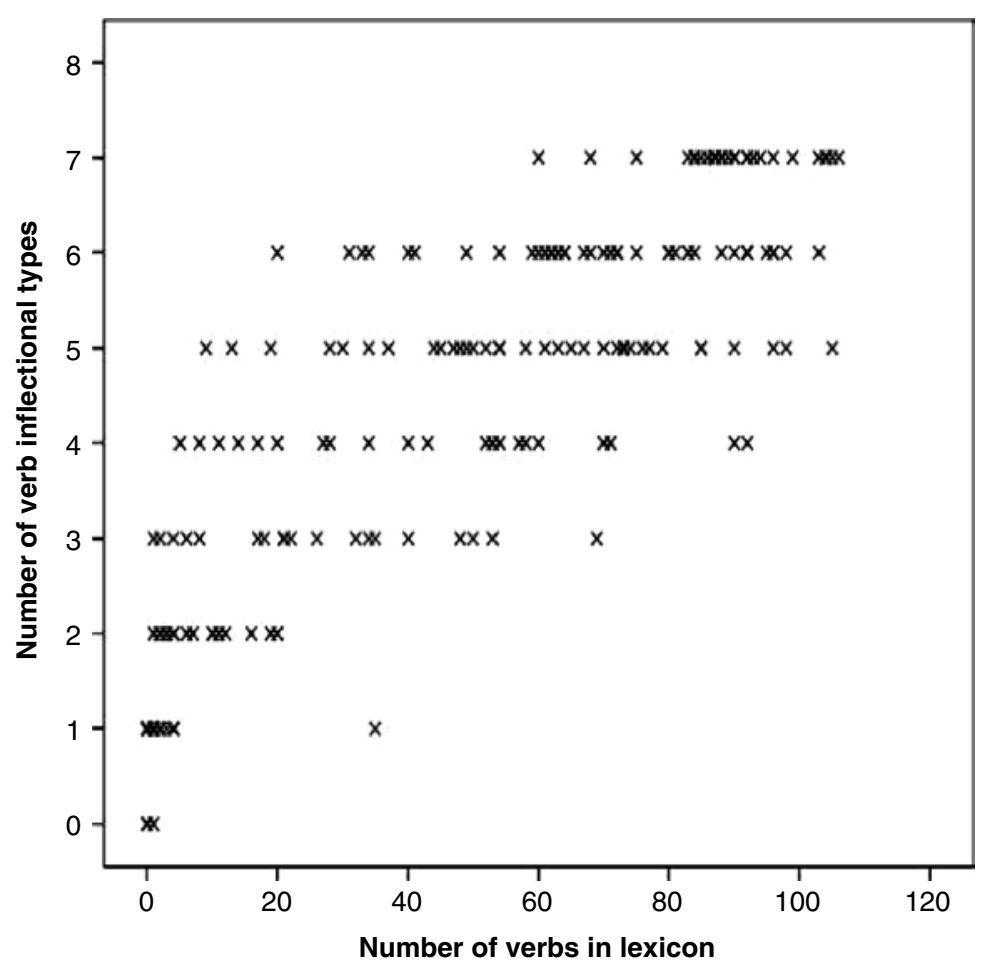

Fig. 5. The number of verb inflectional types in relation to the number of verbs in lexicon.

\section{DISCUSSION}

The present study provides a detailed analysis of the emergence of grammar in relation to lexical growth in children acquiring a highly agglutinative language, Finnish. The findings of this cross-sectional sample clearly showed that children acquired their grammatical knowledge in relation to the growth of their vocabulary size. Further, the acquisition of the two inflectional systems of Finnish differed, when analyzed in relation to the lexicon in which these inflections are used. For the case form types, the strongest growth occurred when the nominal lexicon size was roughly between 50 and 250 words, whereas verb inflectional types were acquired steadily, actively right from the beginning of the verb lexicon acquisition. Thus, the growth of the case form types occurred in a more non-linear manner than verb inflectional types, which were clearly acquired linearly. A larger nominal lexicon size was needed for the case form types other than just basic forms to emerge, when compared to the verb lexicon size for verb inflectional types other than the basic forms to emerge. Further, there 


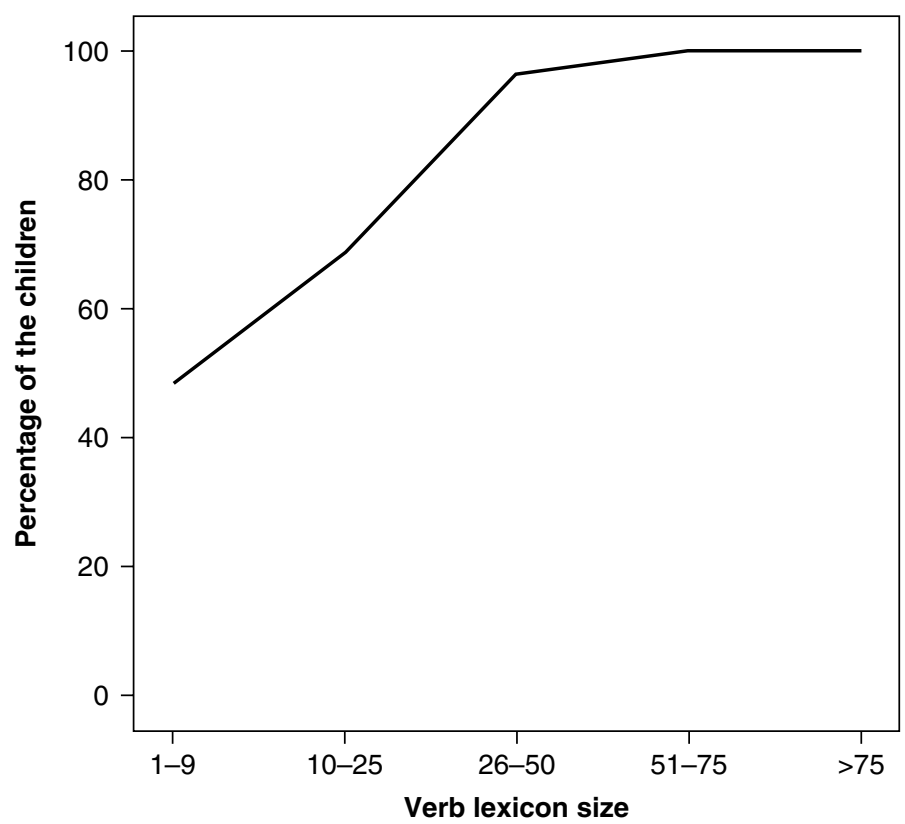

Fig. 6. The percentage of the children reported to have verb inflectional types other than basic verb inflectional types (the third person singular indicative present, the second person singular imperative) only in relation to the growth of the verb lexicon size.

was a strong overall association between different lexical and grammatical measures.

Several findings showed the close association between lexicon and grammar in Finnish children. The number and the proportional share of the closed-class words increased as a function of lexicon size. The emergence of the word combinations was associated with the lexicon size, and the $\mathrm{M}_{3} \mathrm{~L}$ value and the number of morphological inflectional types grew in association with the growth of the vocabulary size. The correlation coefficient values between lexical and grammatical measures were highly significant. The findings indicate that grammatical acquisition is tied to lexicon growth in Finnish children. This phenomenon became even more evident because of the high variation in the lexicon size in this cross-sectional sample at 2 ; 0 . The finding of the close association between lexicon and grammar at the end of the second year is in line with those reported in children acquiring English (e.g. Bates et al., I 995), Italian (Caselli et al., I 999), Hebrew (Maital et al., 2000), Icelandic (Thordardottir et al., 2002) and German (Szagun et al., 2006) as their first language. In the present study this association was described in detail in a typologically different, highly 
TABLE 4. Spearman's correlation coefficient values between the values derived from the Finnish version of the Communicative Development Inventory (FinCDI) and those analyzed from spontaneous speech $(\mathrm{N}=35)$

\begin{tabular}{|c|c|c|c|c|c|c|}
\hline & \multicolumn{6}{|c|}{ Speech } \\
\hline & $\begin{array}{l}\text { Word types } \\
\text { in speech }\end{array}$ & $\begin{array}{c}\text { Nominal } \\
\text { word types }\end{array}$ & $\begin{array}{l}\text { Verb } \\
\text { types }\end{array}$ & $\begin{array}{l}\text { All infl. } \\
\text { types }\end{array}$ & $\begin{array}{l}\text { Case form } \\
\text { types }\end{array}$ & $\begin{array}{l}\text { Verb infl. } \\
\text { types }\end{array}$ \\
\hline \multicolumn{7}{|l|}{ FinCDI } \\
\hline Lexicon size & $\begin{array}{c}0.52 \\
p<0.0 \mathrm{I}\end{array}$ & & & & & \\
\hline $\begin{array}{l}\text { Nominal lexicon } \\
\text { size }\end{array}$ & & $\begin{array}{l}0.27 \\
n . s .\end{array}$ & & & & \\
\hline $\begin{array}{l}\text { Verb lexicon } \\
\text { size }\end{array}$ & & & $\begin{array}{c}0.64 \\
p<0.000 \mathrm{I}\end{array}$ & & & \\
\hline $\begin{array}{l}\text { All inflectional } \\
\text { types }\end{array}$ & & & & $\begin{array}{c}0.7 \mathrm{I} \\
p<0.000 \mathrm{I}\end{array}$ & & \\
\hline $\begin{array}{l}\text { Case form } \\
\text { types }\end{array}$ & & & & & $\begin{array}{c}0.64 \\
p<0.000 \mathrm{I}\end{array}$ & \\
\hline $\begin{array}{l}\text { Verb inflectional } \\
\text { types }\end{array}$ & & & & & & $\begin{array}{c}0.55 \\
p<0.00 \mathrm{I}\end{array}$ \\
\hline
\end{tabular}

TABLE 5. The order of appearance of the morphological inflectional types in the Finnish version of the Communicative Development Inventory (FinCDI) and the same inflectional types in spontaneous speech in the sample of 35 children

\begin{tabular}{|c|c|c|c|c|c|}
\hline Case form types & $\begin{array}{c}\text { FinCDI } \\
\%\end{array}$ & $\begin{array}{l}\text { Speech } \\
\%\end{array}$ & $\begin{array}{c}\text { Verb inflectional } \\
\text { types }\end{array}$ & $\begin{array}{c}\text { FinCDI } \\
\%\end{array}$ & $\begin{array}{c}\text { Speech } \\
\%\end{array}$ \\
\hline Partitive & $97 \cdot \mathbf{I}$ & $88 \cdot 6$ & $2 \mathrm{~S}$ imp. & $97 \cdot \mathbf{I}$ & $74 \cdot 3$ \\
\hline Illative & $88 \cdot 6$ & $74 \cdot 3$ & ${ }_{3} \mathrm{~S}$ ind. & $97 \cdot \mathrm{I}$ & $94 \cdot 3$ \\
\hline Genitive & $97 \cdot \mathbf{I}$ & $45 \cdot 7$ & ${ }_{3} \mathrm{~S}$ ind. neg. & $94 \cdot 3$ & $65 \cdot 7$ \\
\hline Plural form & $85 \cdot 7$ & $45 \cdot 7$ & ${ }_{3} \mathrm{~S}$ ind. pret. & 80.0 & $68 \cdot 6$ \\
\hline Adessive & $77 \cdot \mathbf{I}$ & $65 \cdot 7$ & Passive & $77 \cdot \mathbf{I}$ & $45 \cdot 7$ \\
\hline Inessive & $65 \cdot 7$ & $7 \mathrm{I} \cdot 4$ & IS ind. & $3 I \cdot 4$ & $34 \cdot 3$ \\
\hline Allative & $62 \cdot 9$ & $48 \cdot 6$ & ${ }_{3} \mathrm{~S}$ perfect & $40 \cdot 0$ & $2 \cdot 9$ \\
\hline Elative & $57 \cdot I$ & $34 \cdot 3$ & & & \\
\hline Ablative & $42 \cdot 9$ & $28 \cdot 6$ & & & \\
\hline
\end{tabular}

$\mathrm{I} S=$ first person singular (likewise second and third), neg.=negation, pret.=preterite, imp. $=$ imperative, ind. $=$ indicative.

agglutinative language than those studied so far. Hence, the present results extend those of the earlier ones. The information that grammatical acquisition is associated with lexicon growth in a regular manner is important for those working in clinical practice: it gives predictability to early language acquisition. It is important to know the typical patterns of language acquisition well before the problems can be detected. Grammatical 
acquisition in relation to lexical growth has not been analyzed and described in detail in Finnish children before.

The emergence of the word combinations was associated with lexical growth. Nearly all children (9I \%) with lexicons between IOI-200 words, and all children with vocabularies $>20 \mathrm{I}$ words, combined words. Lexicon sizes in children without word combinations varied between 5 and I 6 words. These findings suggest that the emergence of early syntactic structures is tied, at least partially, to lexicon size, and not necessarily to the age of a child. The result also supports the view that some 'critical mass' of lexical items is required for the emergence of combinatorial productions. Anisfeld et al. ( 1998) reported that lexical accelerations occurred at the time children began to produce word combinations. Although lexical acceleration was not analyzed in the present study, the finding is parallel with the present one. Anisfeld et al. (i998) propose that the child's entry to grammatical language creates a need for specificity of expression, and thus a need for increased vocabulary. Our finding supports this view.

Differences were detected in the acquisition of the two inflectional systems of Finnish when analyzed in relation to the corresponding lexicon, suggesting that different grammatical structures display different degrees and types of lexical dependence (Bates \& Goodman, i 997 : 524). The acquisition of the nominal inflectional types (i.e. case form types, plural ending) occurred in a more non-linear manner, when analyzed in relation to the growth of the nominal lexicon, when compared to the acquisition of the verb inflectional types analyzed respectively, in relation to the verb lexicon size. The acquisition of the case form types supports the 'critical mass' hypothesis proposing that children needed to acquire a number of nominal words first before the growth of case form types could begin. This finding is parallel with those of the non-linear association between lexicon and grammatical growth (e.g. Bates \& Goodman, I997; see however Dixon \& Marchman, 2007). The steady growth of verb inflectional morphology right from the beginning of verb lexicon acquisition is inconsistent with the conclusions based on the findings in English (Marchman \& Bates, I 994) and Icelandic (Thordardottir et al., 2002) children, however. These differences may be explained by differences in the verb inflectional morphology of Finnish compared to that of English or Icelandic (compare Thordardottir et al., 2002): it may be that because of the intensive verb inflectional morphology, Finnish children start to pay attention to verb endings 'earlier' (i.e. already with small verb lexicon sizes) compared to those children acquiring language with less intensive verb inflectional morphology. However, there is an extensive nominal inflectional system in Finnish as well, and these inflectional types were acquired in a more non-linear manner. Could the different acquisition order of nominal words, nouns especially, and verbs explain these differences in the acquisition of the two 
inflectional systems of Finnish? There is reorganization in vocabulary composition during early lexical acquisition (Bates et al., I 994). There is a rapid increase in the acquisition of the nouns in small lexicons ( $<50$ words), and the proportion of nouns is very high (roughly $55 \%$ from the total vocabulary) when children have approximately 50-200 words in their vocabulary. The acquisition of verbs is slower and the development of the proportional share of verbs is steady, linear in shape, when analyzed in relation to the growth of the lexicon size (Bates et al., I994; in Finnish children Stolt et al., 2007; Stolt et al., 2008). In the present study, there was a rapid increase in the acquisition of the nominal inflectional types right when the proportional share of nouns is very high in the lexicons. The verb inflectional types were acquired in more of a linear manner. Thus, it may be that as the proportional share of nouns is very high in the lexicon, children start to pay attention to the suffixes added to these words, and then acquire nominal inflections parallel with the growth of the nominal lexicon. Because there is no such rapid increase in the proportional share of verbs, there is no rapid increase in the acquisition of verb inflectional types either.

The analysis based on the early basic forms made it possible to detect roughly the point at which, in relation to the respective lexical growth, children start to acquire different morphological types (Bittner et al., 2003) instead of using few early, lightly marked forms. A larger nominal lexicon size was needed for the case form types other than basic forms to emerge, when compared to the verb lexicon size for verb inflectional types other than the basic forms to emerge. Also this finding suggests that Finnish children acquire nominal and verb inflectional types in relation to the respective lexicon qualitatively differently. One explanation for this may be the different character of the lexical items to which the inflections are tied. Nouns referring to concrete objects are easier to grasp than verbs expressing relational meanings between the words in sentences, and presumably at least partially because of this, nouns are acquired at a faster rate than verbs (Gentner \& Boroditsky, 200I). If, in the acquisition process, the morphological growth is tied to the growth of the respective lexicon, then the different character, and different growth rates, of these words might explain the differences between the emergence of the nominal and verbal morphology.

In addition to the differences detected in the acquisition of case form and verb inflectional types when analyzed in relation to the respective lexicon, the strong associations between different types of lexical and grammatical measures (i.e. between nominal lexicon size and verb inflectional types, between verb lexicon size and nominal inflectional types) were found. This result, together with other findings of the present work, supports the view that children use different strategies when acquiring their lexical and grammatical knowledge at the end of the second year. Thus, although 
nominal and verbal inflections were acquired in close association with the lexicon in which they are used, other strategies were also used. It is possible that as children have acquired enough different types of words (i.e. nouns, verbs, closed-class words) they become more skilful in analyzing what kind of word endings are added to different types of words. The acquired semantic information helps children in the morphological acquisition (i.e. semantic bootstrapping). Alternatively, children may use acquired grammatical knowledge (i.e. suffixes added to words stems, structural information) for semantic acquisition (i.e. syntactic bootstrapping). It is also possible that both mechanisms are in use as detected in English children between ages 2; 0 and 3; (e.g. Dionne et al., 2003).

The basic forms used in the analysis were those described in the literature (Laalo, 2002, 2003: Toivainen, I980). However, some children were also using forms other than those described by Laalo (2002, 2003) and Toivainen ( 1980 ) at the very beginning of the morphological acquisition in the present sample. Illative was used early for the case form types, and the ${ }_{3} \mathrm{~S}$ negative construction ( $\mathrm{ei}$ oo ' is not') for the verb inflectional types. It has been described (Laalo, 2002, 2003) that illative might be among those forms used at the very beginning of morphological acquisition, but, to our knowledge, the use of ${ }_{3} \mathrm{~S}$ negative construction has not been described earlier. Further, the present approach differs slightly from that of earlier studies (e.g. Marchman \& Bates, I994), which are based on the error analysis of regular and irregular verbs, and are trying to detect the emergence of productivity in morphological acquisition. The findings based on the analysis of early basic and non-basic forms informs about the emergence of inflectional types, thus of one feature of early morphological acquisition only. Further analysis of morphological acquisition (e.g. token analysis, error analysis) in relation to lexical growth would be useful to fully understand how Finnish children acquire their early morphology.

The acquisition order of the case form and verb inflectional types in the present study was roughly the same as in earlier studies (Laalo, 2002, 2003; Toivainen, I980, I997). As reported by Toivainen (I980) for case form types, illative, genitive and adessive were among those forms acquired after nominative and partitive. Elative and ablative were used least in both studies. For the verb inflectional types, the order of appearance was nearly the same as reported by Toivainen (I980; see also Laalo, 2003, 2003). There were minor differences between the earlier and the present findings, however. For example, the order of appearance of adessive, inessive and allative differed slightly in the present and in Toivainen's (I980) study. Further, in Toivainen's ( 1980 ) sample the ${ }_{3} \mathrm{~S}$ indicative form was acquired before the ${ }_{3} \mathrm{~S}$ negative construction, and the $\mathrm{I} S$ indicative form before the passive. These differences between the findings may be due to the difference in sample size and the methodology used. 
The present findings were based on the data gathered using the structured maternal rating method, the FinCDI. The findings were highly parallel with those reported in the normative study of the FinCDI (the mean number of words $278, S D$ I 63 ; mean number of inflectional types $9 \cdot 3$, $S D$ 5.०; mean $\mathrm{M}_{3} \mathrm{~L} 5 \cdot 7, S D$ 3.0 at 2; \%; Lyytinen, I 999). Also most correlation coefficient values between the results of the structured parental rating method and the values analyzed from spontaneous speech from videotaped interactions were significant, as were the correlation coefficient values between the measures derived from the FinCDI and the MDI value in BSID II. These findings provided support for the use of FinCDI when evaluating lexical and grammatical growth of Finnish children at the end of the second year. The fact that the correlation between the nominal lexicon size in FinCDI and the number of the nominal words used in spontaneous speech was not significant may be explained by the matter that nouns are among the first acquired and the most used words in early lexicons (Bates et al., I994; Gentner \& Boroditsky, 2001). Thus, most children had nouns in their lexicons and used them actively in spontaneous speech, and perhaps therefore the correlation did not reach the significance level. Further, the present study gave information on the emergence of grammar in relation to lexical growth in children at 2;0 only. It is possible that this association is different in younger or older children than the one detected in the present work.

There are many matters, such as gender or birth order, which may affect the linguistic development of a child (Fenson et al., r 994). The present sample of I 8 I Finnish children was evenly distributed between boys and girls. All children were developing cognitively normally, verified using BSID II. However, the percentage of the first-borns was slightly higher than if it were in a totally randomized sample (in the randomised sample of I 46 children in the present work $46 \%$ were first-borns; in the total sample of I 8 I children $56 \%$ were first-borns). First-borns proceed at a faster rate in their lexical development than those born later. For example, Bornstein, Leach \& Haynes (2004) reported that first-borns had larger lexicon sizes than second-borns in maternal reports, but no difference was found in spontaneous speech or in formal assessments at i ; 8. Fenson et al. (1994) reported a small, but statistically significant negative correlation between birth order and lexicon size $(r=-0.09, p<0.001)$ and between birth order and the emergence of word combinations $(r=-0.05, p<0.05)$. However, it is possible that the birth order difference accounts for only a very small proportion of the extensive variation found in lexical acquisition during the second year (Fenson et al., I 994). Further, the sample of the present study consisted of the data derived from two different cohorts, in which the data collection varied slightly. This may have affected the findings somewhat (Bornstein, Putnick \& De Houwer, 2006). In addition, one fault of the 
present study was that participants were generally from a high SES group, which may have influenced the findings.

This study provides a detailed description of the emergence of grammar in relation to lexical growth in children acquiring a highly agglutinative language, Finnish. Differences detected in the acquisition of the two inflectional systems of Finnish suggest that different grammatical structures display different degrees and types of lexical dependence (Bates \& Goodman, I 997 : 524). In addition, the strong overall associations detected between different types of lexical and grammatical measures suggested that children use different strategies when acquiring their lexical and grammatical knowledge at the end of the second year. The findings extend the results of previous studies (e.g. Caselli et al., I 999; Thordardottir et al., 2002), and support the view that grammar is not acquired as a separate module independently from the lexicon but in close association with vocabulary acquisition.

\section{REFERENCES}

Anisfeld, M., Rosenberg, E., Hoberman, M. \& Gasparini, D. (I998). Lexical acceleration coincides with the onset of combinatorial speech. First Language 18, I65-84.

Bates, E., Bretherton, I. \& Snyder, L. (1988). From first words to grammar. New York: Cambridge University Press.

Bates, E., Dale, P. \& Thal, D. (1995). Individual differences and their implications for theories of language development. In P. Fletcher \& B. MacWhinney (eds), The handbook of child language, 96- 5 I. Oxford: Blackwell.

Bates, E. \& Goodman, J. (I 997). On the inseparability of grammar and the lexicon: Evidence from acquisition, aphasia and real-time processing. Language and Cognitive Processing I2, $507-584$.

Bates, E. \& Goodman, J. (I999). On the emergence of grammar from the lexicon. In B. MacWhinney (ed.), The emergence of language, 29-80. London: Lawrence Erlbaum Associates Publishers.

Bates, E., Marchman, V., Thal, D., Fenson, L., Dale, P., Reznick, S., Reilly, J. \& Hartung, J. (1994). Developmental and stylistic variation in the composition of early vocabulary. Fournal of Child Language 21, 85-123.

Bayley, N. (1993). The Bayley Scales of Infant Development, and ed. San Antonio, TX: Psychological Corporation.

Bittner, D., Dressler, W. \& Kilani-Schoch, M. (2003). Development of verb inflection in first language acquisition. A cross-linguistic perspective. Berlin: Mouton de Gruyter.

Bornstein, M., Leach, D. \& Haynes, M. (2004). Vocabulary competence in first- and secondborn siblings of the same chronological age. Fournal of Child Language 31, 855-73.

Bornstein, M., Putnick, D. \& De Houwer, A. (2006). Child vocabularly across the second year: Stability and continuity for reporter comparisons and a cumulative score. First Language 26, 299-3 6 .

Caselli, C., Casadio, P. \& Bates, E. (I 999). A comparison of the transition from first words to grammar in English and Italian. Fournal of Child Language 26, 69-I I I.

Clark, E. (2003). First language acquisition. Cambridge: Cambridge University Press.

Dasinger, L. (1997). Issues in the acquisition of Estonian, Finnish, and Hungarian: A crosslinguistic comparison. In Dan Slobin (ed.), The crosslinguistic study of language acquisition, Vol. 4, 87-182. Mahwah, NJ: Lawrence Erlbaum.

Dionne, G., Dale, P., Boivin, M. \& Plomin, R. (2003). Genetic evidence for bidirectional effects of early lexical and grammatical development. Child Development 74, 394-4I 2. 
Dixon, J. \& Marchman, V. (2007). Grammar and the lexicon: Developmental ordering in language acquisition. Child Development 78, i 90-2 I 2.

Fenson, L., Dale, P., Reznick, J., Bates, E., Thal, D. \& Pethick, S. (r994). Variability in early communicative development. Monographs of the Society for Research in Child Development 59, (5, Serial No. 242).

Gentner, D. \& Boroditsky, L. (200I). Individuation, relativity, and early word learning. In M. Bowerman \& S. Levinson (eds), Language acquisition and conceptual development, 2 I 5-56. Cambridge: Cambridge University Press.

Gleitman, L. (I990). The structural sources of verb meaning. Language Acquisition I, 3-55.

Goldberg, A. (I999). The emergence of the semantics of argument structure constructions. In B. MacWhinney (ed.), The emergence of language, I97-212. London: Lawrence Erlbaum Associates Publishers.

Häkkinen, K. (200I). Kielitieteen perusteet. [Basics of linguistics] Helsinki: Suomalaisen kirjallisuuden seura. [Finnish literature association].

Laalo, K. (2002). Acquisition of case in Finnish: A preliminary overview. In M. Voeikova \& W. Dressler (eds), Pre- and protomorphology. Early phases of morphological Development in nouns and verbs, Vol. 29, 83-103. Lincom Studies in Theoretical Linguistics. Munchen: Lincom Europa.

Laalo, K. (2003). Early verb development in Finnish: A preliminary approach to miniparadigms. In D. Bittner, W. Dressler \& M. Kilani-Schoch (eds), Development of verb inflection in first language acquisition, 323-50. Berlin: Mouton de Gruyter.

Lyytinen, P. (I999). Varhaisen kommunikaation ja kielen kehityksen arviointimenetelmä. [The method to evalute early communication and language]. Jyväskylä: Niilo Mäki Säätiö. [Niilo Mäki Foundation].

Lyytinen, P. \& Lyytinen, H. (2004). Growth and predictive relations of vocabulary and inflectional morphology in children with and without familial risk for dyslexia. Applied Psycholinguistics 25, 397-4I I.

Maital, S., Dromi, E., Sagi, A. \& Bornstein, M. (2000). The Hebrew Communicative Development Inventory: Language specific properties and cross-linguistic generalizations. Fournal of Child Language 27, 43-67.

Marchman, V. \& Bates, E. (I 994). Continuity in lexical and morphological development: A test of the critical mass hypothesis. Fournal of Child Language 21, 339-66.

Marchman, V., Plunkett, K. \& Goodman, J. (I997). Overregularization in English plural and past tense inflectional morphology: A response to Marcus (I995). Fournal of Child Language 24, 767-69.

Marcus, G. (I996). Why do children say 'breaked'? Current Directions in Psychological Science 5, $8 \mathrm{I}-85$.

Moyle, M., Weismer, S., Evans, J. \& Lindstrom, M. (2007). Longitudinal relationships between lexical and grammatical development in typical and late-talking children. Fournal of Speech, Language and Hearing Research 5o, 508-528.

Peters, A. (I995). Strategies in the acquisition of syntax. In P. Fletcher \& B. MacWhinney (eds), The handbook of child language, 462-82. Oxford: Blackwell Publishers.

Pinker, S. (I99i). Rules of language. Science 253, 530-35.

Stolt, S., Haataja, L., Lapinleimu, H. \& Lehtonen, L. (2008). Early lexical development of Finnish children - a longitudinal study. First Language 28, 259-79.

Stolt, S., Klippi, A., Launonen, K., Munck, P., Lehtonen, L., Lapinleimu, H., Haataja, L. $\&$ the PIPARI study group (2007). Size and composition of the lexicon in prematurely born very-low-birth-weight and full-term Finnish children at two years of age. Fournal of Child Language 34, 283-3 Io.

Szagun, G., Steinbrink, C., Franik, M. \& Stumper, B. (2006). Development of vocabulary and grammar in young German-speaking children assessed with a German language development inventory. First Language 26, 259-80.

Thordardottir, E., Weismer, S. \& Evans, J. (2002). Continuity in lexical and morphological development in Icelandic and English-speaking 2-year-olds. First Language 22, 2-28.

\section{4}


Toivainen, J. (1980). Inflectional affixes used by Finnish-speaking children aged I-3 years. Helsinki: Suomalaisen kirjallisuuden seura. [Finnish literature association].

Toivainen, J. (1997). The acquisition of Finnish. In Dan Slobin (ed.), The cross-linguistic study of language acquisition, Vol. 4, 87-I 82. Mahwah, NJ: Lawrence Erlbaum.

\section{APPENDIX}

TABLE A I. Description of the case forms in Finnish (Dasinger, I 997; Toivainen, 1997)

\begin{tabular}{|c|c|c|c|}
\hline Case & Suffix & Main function & Example \\
\hline \multicolumn{4}{|c|}{ Grammatical cases } \\
\hline Nominative & $-(\mathrm{sg}),-\mathrm{t}(\mathrm{pl})$ & subject & silmä ‘eye’ \\
\hline Partitive & $-\mathrm{a} /-\ddot{a},--\mathrm{ta} /-\mathrm{tä}$ & $\begin{array}{l}\text { object/subject/ } \\
\text { predicative }\end{array}$ & silmä-ä 'eye' \\
\hline Accusative & $-\mathrm{n}(\mathrm{sg}),-\mathrm{t}(\mathrm{pl})$ & object & silmä-n 'eye' \\
\hline Genitive & $-\mathrm{n}$ & possession & silmä-n 'eye’s' \\
\hline \multicolumn{4}{|c|}{ Inner local cases } \\
\hline Inessive & -ssa/-ssä & 'in’ & silmä-ssä 'in the eye' \\
\hline Elative & -sta/-stä & 'out of' & silmä-stä 'from the eye' \\
\hline Illative & $-\mathrm{hVn},-\mathrm{Vn},-$ seen & 'into' & silmä-än 'into the eye' \\
\hline \multicolumn{4}{|c|}{ Outer local cases } \\
\hline Adessive & -1la/-1lä & 'at/on' & silmä-llä 'on the eye' \\
\hline Ablative & -lta/-ltä & 'from' & silmä-ltä 'from the eye' \\
\hline Allative & $-11 \mathrm{e}$ & 'to' & silmä-lle 'to the eye' \\
\hline \multicolumn{4}{|l|}{ Other cases } \\
\hline Essive & -na/-nä & 'as' & silmä-nä 'as an eye' \\
\hline Translative & $-\mathrm{ksi}$ & 'to/becoming' & silmä-ksi 'to an eye' \\
\hline Abessive & -tta/-ttä & 'without' & silmä-ttä 'without an eye' \\
\hline Comitative & - ne & 'with’ & silmi-ne-en "with his eyes" \\
\hline Instructive & $-n$ & $\begin{array}{l}\text { manner, means, } \\
\text { instruction }\end{array}$ & silmi-n 'with his eyes' \\
\hline
\end{tabular}

TABLE A 2. Description of the verb inflections in Finnish (Dasinger, I997; Laalo, 2003; Toivainen, I997)

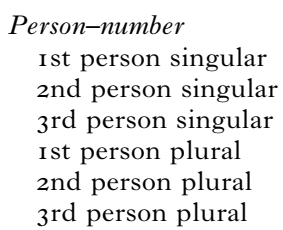

Person-number

Ist person singular 2nd person singular 3rd person singular and person plural 3rd person plural

\author{
minä puhu-n 'I speak' \\ sinä puhu-t 'you speak' \\ hän puhu-u 'he/she speaks' \\ me puhu-mme 'we speak' \\ te puhu-tte 'you speak' \\ he puhu-vat 'they speak'
}

In addition to the person-number markings, verbal morphology for finite verbs can express tense (present, preterite, perfect and past perfect), voice (active and passive) and mood (indicative, imperative, conditional, potential). The unmarked forms are non-past, active and indicative. Other 
meanings are expressed using a distinct form. Verbs in the passive mode are not inflected for person and number. Negation is expressed using a negative auxiliary conjugated for person and number. The marking of perfect aspects is built up using the verb 'to be' (olla) in conjugation with participle forms of verbs (Dasinger, I997; Toivainen, I997). 